\title{
Old-field Community, Climate and Atmospheric Manipulation DE-FG02-02ER63366
}

\author{
Aimée T. Classen, University of Tennessee
}

The Old-field Community, Climate and Atmospheric Manipulation (OCCAM) project was harvested in June 2008. We are in the process of finishing a number of laboratory, growth chamber and greenhouse projects, analyzing data, and writing papers. The projects completed in 2008 as well as the ones that are still ongoing are outlined below.

\section{Aboveground Plant Responses}

How do climate and atmospheric changes alter aboveground plant biomass and community structure?

- Aboveground biomass was harvested by clipping in June 2008. All samples will be dried and weighed to compare biomass production between treatments and across years. In 2007 , plant community biomass was reduced by $55 \%$ in dry treatments $(P<0.0001)$ relative to wet treatments and stimulated by elevated $\mathrm{CO}_{2}(\mathrm{P}<0.0034)$. The two dominant species, Lespedeza and Festuca, were reduced in dry relative to wet treatments $(P<0.001$ and $\mathrm{P}<0.0149$, respectively).

Effects of multiple climate changes factors on plant community composition and diversity: what did we learn from a 5-year open-top chamber experiment using constructed old-field communities?

- Preliminary analyses show that treatment effects on plant community composition (based on plant cover) and diversity (calculated as Simpson's Evenness) were not consistent across year (2003-2007). For example, significant treatment effects in one year were not found in the year after. Other effects just became apparent after three or four years. Starting from seedlings in 2003, there were strong inherent (i.e. successional) changes in plant community composition and, hence, diversity, from the beginning towards the end of the experiment in 2008. Most likely, such inherent changes in plant community composition have strongly interacted with the $\mathrm{CO}_{2}, \mathrm{~T}$ and $\mathrm{H}_{2} \mathrm{O}$ treatments in shaping the plant communities across 2003-2008. Univariate and mulitvariate analyses - including the latest 2008 data - are in progress.

- Plant community composition and plant cover. Across the 2007 growing season (April October), differences in plant species composition (based on monthly plant cover measurements) could significantly be explained by the climate change treatments (RDA, MC Permutation tests, $\mathrm{F}=6.04, \mathrm{P}=0.02$ ). However, $\mathrm{CO}_{2}, \mathrm{~T}$ and water differed markedly in their effects. Water significantly explained variation in plant species composition, whereas $\mathrm{CO}_{2}$ and $\mathrm{T}$ did not. However, the effect of water depended on $\mathrm{CO}_{2}$ and $\mathrm{T}$ treatments, as indicated by their significant interaction with water (RDA, MC Permutation tests, $F=11.50$, $P=0.01$ and $\mathrm{F}=13.51, P<0.01)$. Lespedeza and Festuca were the most dominant species in the plant community. Averaged across the season, together they accounted for $63 \%$ of total species cover. Lespedeza and Festuca differed in their response to the climate change treatments. From April to October, proportional cover of Lespedeza became higher in wet than in dry plots (water $\times$ time: $F_{1,120}=7.77, P<0.01$ ). There was a marginally significant $\mathrm{CO}_{2} \times$ time interaction (RANOVA: $F_{1,120}=3.11, P=0.08$ ), which could be attributed to higher proportional cover of Lespedeza under ambient than under elevated $\mathrm{CO}_{2}$ early in the season. Proportional cover of Festuca was higher in wet than in dry plots early in the season, but this pattern reversed toward the end of the season (water $\times$ time: $F_{1,120}=9.01, P<0.01$ ). Proportional cover of Festuca was marginally significantly higher at 
high than at low $T\left(F_{1,39.4}=3.76, P=0.06\right)$, and there was a marginally significant $\mathrm{CO}_{2} \times \mathrm{T}$ $\times$ Time interaction $\left(F_{1,120}=3.65, P=0.06\right)$. Other single and interactive effects of climate change treatments on the proportional cover of Lespedeza and Festuca during the 2007 season were not significant.

Do atmospheric and climatic change factors interact to alter woody seedling emergence, establishment and productivity?

- To investigate if atmospheric and climatic change factors interact to alter woody seedling emergence we introduced woody seeds into the OCCAM experiment in 2007. Overall, there were significant temperature $\times$ species $(F=5.52 ; P<0.008)$ and water $\times$ species $(F$ $=13.37 ; \mathrm{P}<0.0001$ ) interactions on seedling emergence. There were no overall effects of the treatments on seedling mortality. The most striking response we observed was the drastic reduction in maple emergence in dry treatments. Only five seedlings, out of 120 planted seeds, emerged in dry plots and soil moisture was the most significant predictor of seedling emergence explaining $23 \%$ of the variation. Treatment effects on the other species were, compared to maple, subtle. In fact, there was no effect of the treatments on pine emergence and the interactive effect of $\mathrm{CO}_{2}$ and warming on sweetgum emergence was not striking, although it was statistically significant. It is unlikely that $\mathrm{CO}_{2}$ had any direct effect on germination and seedling emergence, processes that would not benefit from a $\mathrm{CO}_{2}$ effect on photosynthesis. We assume there must be an indirect influence through past or current effects on the old-field vegetation. In fact, when examining the data using a multiple regression, $25 \%$ of the variation in pine emergence $(F=13.65, P=0.001)$ and 14 $\%$ of maple emergence $(F=4.55, P=0.45)$ was explained by total plant community cover, suggesting that changes plant community growth can have a strong influence on emergence.

- Seedling establishment continued to be monitored until June 2008. All seedlings were harvested in June and are being processed for plant height, leaf area, stem diameter, wood density, and mycorrhizal root colonization. Initial results suggest that sweetgum growth and pine height was significantly reduced in dry relative to wet treatments. Pine growth was also stimulated in elevated $\mathrm{CO}_{2}$ and elevated temperature treatments relative to other treatment combinations.

\section{Belowground Responses}

Soil moisture surpasses elevated $\mathrm{CO}_{2}$ and temperature in importance as a control on soil carbon dynamics

- Following four growing seasons, elevated $\mathrm{CO}_{2}$ had no measurable effect on carbon and nitrogen concentrations in whole soils, particulate organic matter (POM), and mineralassociated organic matter (MOM). Soil moisture was the principal factor affecting soil carbon dynamics. Analysis of stable carbon isotopes, under elevated $\mathrm{CO}_{2}$, indicated that the fraction of new carbon increased significantly over four years in whole soils, POM, and MOM, but that gains were reduced in a simulated drought treatment. Despite high rates of $\mathrm{N}_{2}$-fixation and significant belowground inputs of new soil organic matter, soil carbon and nitrogen concentrations and carbon stocks in POM declined significantly over four years under conditions of higher soil moisture that corresponded to prevailing precipitation inputs (1300 mm $\mathrm{yr}^{-1}$ ). Reduced soil moisture lowered soil respiration and resulted in overall slower soil carbon cycling under elevated $\mathrm{CO}_{2}$. Higher soil moisture produced in a net decline in soil carbon stocks and a widening of soil $\mathrm{C}: \mathrm{N}$ ratios. In this experiment, differences in soil moisture surpassed elevated $\mathrm{CO}_{2}$ and temperature in importance as a control on soil carbon dynamics. At our location, the findings indicate that a drier climate 
(i.e., reduced soil moisture) in a $\mathrm{CO}_{2}$-rich world will help to preserve old-field soil organic matter. This paper is currently in review at Plant and Soil.

How do climate and atmospheric changes alter belowground root and fungl biomass?

- We are combining the long-term (2003-2008) minirhizotron data set with continuous, rootspecific measurements of root mass and root [N]. A series of soil cores were taken adjacent to the minirhizotron tubes in July, 2008. Fine roots were washed from each soil core. Root morphological characteristics, including total length, volume and diameter distribution will be determined early this fall. The diameter-biomass-[N] relationships determined from these data will be used to extrapolate length and diameter measurements from a long-term minirhizotron data set to estimates of carbon and nitrogen input to the soil system.

- Fungal hyphal production and nutrient content data were collected using hyphal ingrowth cores. Cores incubated in each treatment were removed every six weeks over the course of the 2008 growing season. Collected cores are still being sorted to assess hypal production in each of the treatments. Ongoing at UT

How do climate and atmospheric changes alter soil microarthropod and microbial communities?

- Effects of elevated $\mathrm{CO}_{2}$, warming, and changes in soil moisture on the diversity of soil microarthropod communities. Microarthropods were extracted from soil cores collected in November 2007 and June of 2008 with high-gradient Tullgren funnels. Specimens were sorted to species and morphospecies. Overall microarthropod abundance was low. There were no treatment effects on microarthropod richness and abundance in June. In November, there was greater microarthropods richness in wet plots relative to dry plots $(\mathrm{F}=$ 8.96, $\mathrm{p}=0.0086$ ) and under elevated $\mathrm{CO}_{2}$, warming decreased microarthropod richness $\left(\mathrm{CO}_{2} \times\right.$ temperature; $\left.\mathrm{F}=6.61, \mathrm{p}=0.0205\right)$. Ongoing at $\boldsymbol{U T}$

- Effects of elevated $\mathrm{CO}_{2}$, warming, and changes in soil moisture on the diversity and function of bacterial communities. DNA and RNA were extracted from soils in each treatment. Cloned libraries of the PCR-amplified 16S rRNA and citrate synthase genes were constructed, sequenced, and phylogenetic analyses were conducted. The bacterial 16S rRNA cloned libraries revealed great diversity, with the majority of sequences related to the Proteobacteria phylum (ca. 50\%). The patterns of response in abundance for the different phylogenetic phylum were highly complex. Results to date indicate that climate drivers and their interactions select for distinct microbial populations, however the response is complex. This work was supported by an ORNL internal grant.

- Citrate synthase: a functional genetic marker to study effects of climate drivers on soil microbial communities? Until recently few studies have used functional markers to assess the response of microbial soil communities to climatic stressors. Soil respiration is an integrator of soil microbial community function and is highly responsive to changes in temperature and moisture. Thus, we used citrate synthase as a functional marker to better understand how soil microbial communities respond to climatic change because citrate synthase is involved in soil respiration. Results to date suggest that the soil microbial community composition may be more responsive to climate drivers than the overall abundance of the functional marker.

How do climate and atmospheric changes alter belowground microbial function?

- Effects of elevated $\mathrm{CO}_{2}$, warming, and changes in soil moisture on soil microbial function. In collaboration with Argonne National Lab, we utilized phospholipid fatty acid (PLFA) analysis to characterize the direct and interactive effects of our treatments on the 
composition of the soil microbial community. Briefly, total PLFA was extracted from soil samples collected on four dates in 2004 and 2005, and individual fatty acids were identified using gas chromatography/mass spectrometry. Results to date indicate that elevated $\mathrm{CO}_{2}$ concentrations increased the relative abundance of fungal PLFA and decreased the relative abundance of bacterial PLFA, while elevated temperature had the opposite effect. The effects of elevated $\mathrm{CO}_{2}$ concentration and temperature, however, varied according to water availability. For example, under wet treatments, the relative abundance of bacterial PLFA was significantly higher in elevated temperature plots than in ambient temperature plots, but under dry treatments, there was no difference between elevated temperature and ambient temperature plots. Additionally, under dry treatments, the relative abundance of arbuscular mycorrhizal fungi was higher in elevated $\mathrm{CO}_{2}$ plots than in ambient $\mathrm{CO}_{2}$ plots, but under wet treatments, there was no difference between elevated and ambient $\mathrm{CO}_{2}$ plots. These results suggest that water availability plays an integral role in determining the capacity of the soil microbial community to adjust to a changing environment.

Linking root litter diversity and microbial functioning at a micro scale under current and projected $\mathrm{CO}_{2}$ concentrations.

- Multi-species litter frequently decomposes at a faster rate than would be expected from individual species decomposition rates. The mechanisms responsible for a synergistic effect of litter diversity on decomposition rates have not yet been underpinned, nor has the impact of elevated atmospheric $\mathrm{CO}_{2}$ on this process been evaluated. We will incubate both individually and in mixture Festuca pratense, Trifolium repens and Lespedeza cuneata root litter in soil derived from the ambient and elevated $\mathrm{CO}_{2}$ plots in the OCCAM experiment. Our objectives are to 1) determine how addition of root litter to soil from a variety of species versus single species affects activity and diversity of soil microbes 2 ) how combining root litter from a variety of species versus single species affects soil macro- and microaggregate formation 3) whether soil microbial activity, diversity and aggregate formation are positively linked, and 4) how previous long-term exposure of roots and soil to elevated $\mathrm{CO}_{2}$ alters microbial activity, diversity and aggregate formation and the interactions between them. Microbial activity will be determined by $\mathrm{CO}_{2}$ respiration measurements. We will take advantage of the differences in isotopic $13 \mathrm{C}$ signature between ambient and elevated $\mathrm{CO}_{2}$ treatments by incubating roots exposed to elevated $\mathrm{CO}_{2}$ in soil exposed to ambient $\mathrm{CO}_{2}$ and vice versa, which enables us to partition between root and native SOM decomposition. The soil will be fractionated in aggregates with different size classes as well as particulate organic matter by wet-sieving and using a micro-aggregate isolator. Microbial community structure will be determined using qPCR and TRFLP. Ongoing at UT

\section{Aboveground - Belowground Interactions}

Multifactor climate change effects on soil ecosystem functioning depend on concurrent changes in plant community composition.

- To better understand and predict effects of climate change on soil ecosystem functioning, it is necessary to distinguish primary effects (i.e., direct effects and effects through common changes in plant physiology) from secondary effects through changes in plant species composition. We hypothesized that primary climate change effects on soil ecosystem functioning, as indicated by potential extracellular enzyme activities and soil nematode community composition, depend on or are outweighed by climate change-induced alteration of plant community composition (e.g., secondary effects). At the end of the 2007 growing season, we measured activity of nine extracellular enzymes that take part in degrading a variety of compounds involved in carbon and nutrient cycling and we analysed soil nematode community composition at the taxonomic level (genus / family) and at the 
'feeding group' level. Enzyme activities and nematode communities were measured in the bulk soil (to test net treatment effects) and in soils collected under the two dominant plant species, Lespedeza cuneata and Festuca pratense (to test species-specific effects within the coordinating treatments).

- For the bulk soil samples, we found few effects of climate change treatments on enzyme activities. However, $\beta$-Xylosidase activity was decreased in dry plots of chambers with elevated $\mathrm{CO}_{2}$ and in dry plots of chambers with elevated T. Irrespective of water, $\beta$ xylosidase activity was decreased both at ambient $\mathrm{CO}_{2}$, elevated $\mathrm{T}$, and at elevated $\mathrm{CO}_{2}$, ambient T. Generally, $\mathrm{CO}_{2}$ and $\mathrm{T}$ had less effect on enzyme activities than water. Enzyme activities measured in plant species-specific soils differed considerably from activities measured in the bulk soil. Activity of phosphatase, sulfatase, phenoloxidas, and peroxidase, was significantly lower in dry than in wet plots, while the opposite was the case for cellobiohydrolase. For four of the nine enzymes (phosphatase, NAGase, $\beta$-glucosidase, sulfatase) activity was significantly lower in soils collected under Lespedeza than in soils collected under Festuca. Except a marginally significant Species $\times$ water interaction for phosphatase, effects of plant species and effects of water were independent of each other. There was a significant species $\times \mathrm{CO}_{2} \times \mathrm{T}$ interaction for NAGase and a significant species $\times \mathrm{T} \times$ water interaction for $\beta$-glucosidase. When enzymes activities were analyzed at the community level, there were significant effects of plant species and $\mathrm{H}_{2} \mathrm{O}$, and there was a significant interaction between plant species and water. Similarly, we found significant species $\times \mathrm{CO}_{2}$ and species $\times \mathrm{CO}_{2} \times$ water interactions. The interactive effects of species $\times$ $T$ and species $\times T \times$ water were marginally significant. These species $\times$ treatment interactions indicate at plant species-specific profiles of enzyme activities in response to the climate change. Phosphatae, cellobiohydrolase, and $\beta$-glucosidase contributed most to the community response. At the community level, there was also a significant interactive effect of $\mathrm{CO}_{2} \times$ water. Single effects of $\mathrm{CO}_{2}$ and $\mathrm{T}$ on enzyme activities were small and largely insignificant, both at the community level and for individual enzymes.

- Generally, numbers of nematodes found in OCCAM soil were low. The total number of nematodes, as well as total numbers of plant-feeders, endo-parasitic plant-feeders, root hair-feeders, and bacterial-feeders were lower in dry than in wet treatments. Generally, the effect of the water treatment was stronger in soils under Festuca than in soils under Lespedeza. Numbers of nematodes under Lespedeza were low, except for fungal-feeders and omnivorous nematodes. Fungal-feeding nematode tended to be more abundant under Lespedeza than under Festuca, but only in wet treatments. Omnivorous nematodes were more abundant under Lespedeza than under Festuca. $\mathrm{CO}_{2}$ and $\mathrm{T}$ had little effect on soil nematode communities. Interactive effects between water and plant species indicate that effects of climate change treatments (e.g. altered precipitation regimes) can depend on the plant species considered. Also, nematode communities under Lespedeza indicated more fungal-based decomposition pathways, while nematode communities under Festuca indicated more bacterial-based decomposition pathways. So, climate change induced shift in plant community composition (e.g. shift in proportional cover of Festuca and Lespedeza in response to the water treatments) can, indirectly, affect soil ecosystem functioning. Multivariate analyses of nematode feeding group composition showed that water $(27 \%)$, plant species $(6 \%)$ and their interaction (17\%) could explain significant parts of the variation. We also showed significant interactive effect of $\mathrm{CO}_{2} \mathrm{x}$ water and $\mathrm{CO}_{2} \mathrm{x}$ water $\mathrm{x}$ species on nematode feeding group composition. Within feeding groups, nematode taxa responded differently to the treatments and the plant species. Multivariate analyses of the nematode taxon composition revealed that root hair-feeding Tylenchidae, and opportunistic bacterial-feeding Cephalobidae, Rhabditidae and Plectidae were associated with the wet treatments, while endo-parasitic plant-feeding Heteroderidae were stronger associated with 
dry treatments. Root hair-feeding Psilenchus associated with Festuca; omnivorous Qudsianematida and fungal-feeding Diphterophora associated with Lespedeza.

- Soil Legacy Effects. Starting in August 2008 a growth chamber experiment will be initiated to test the soil-carry over effects of the OCCAM treatment on plant performance, fitness, and plant competitive interactions (using Lespedeza, Festuca, Solidago, and Plantago).

This experiment will test to what extent observed effects of the OCCAM treatments on plant community composition could be attributed to changes in the soil, and specifically to changes in the soil microbial community. We will use live soils and microbial inocula (sterilized or non-sterilized) extracted from OCCAM bulk soils. We will analyze seedling mortality, shoot/root biomass, soil properties, with potential for microbial analyses of the soil and of the microbial inocula. Ongoing at UT

- Plant-parasitic nematodes and root chemistry. In collaboration with aboveground insect community analyses (see below section), associated root samples were collected from each plant and will be analyzed for plant-parasitic nematodes, mycorrhizal colonization, and root chemistry. The combined analyses will proved a more complete picture of the effects of climate change on above-and belowground herbivory in old-field communities. Ongoing at UT

\section{Work ongoing in collaboration with other institutions:}

How do climate and atmospheric changes alter aboveground insect populations?

- Researchers at Appalachian State University (Ray Williams) investigated how elevated $\mathrm{CO}_{2}$, elevated temperature and reduced soil water altered the insect community by quantifying morphospecies abundance and diversity. Using a combination of sticky traps and vacuum sampling they sampled insects that naturally colonized the plant community. Insects were identified to morphospecies and the insect community with respect to abundance, richness and evenness quantified. Although there were occasional effects of $\mathrm{CO}_{2}$ and water treatment, the effects of warming on the insect community were large and consistent. Non-metric multidimensional scaling in concert with analysis of similarity found that only temperature affected insect community composition. Results suggest that climatic warming may alter certain insect communities via effects on insect species most responsive to a higher temperature, contributing to a change in community structure. A continuation of this work began in June 2008, with the collection of three plant species within the larger community (Solidago, Trifolium and Dactylis). Insects directly associated with these species will be identified and quantified to more fully elucidate potential treatment effects on specific plant-insect species interactions. In addition, samples were collected to quantity leaf area removal in order to provide insight into mechanisms acting within plant-insect communities with respect to climate change.

How do climate and atmospheric changes alter festuca endophyte infection?

- Researchers at the University of Kentucky (Rebecca McCulley) collected festuca samples in all of the treatments prior to the harvest to assess endophyte infestation. Thus far, they have found that over $85 \%$ of the festuca plants harvested were infected with endophytes with a slightly higher infection rate in wet relative to dry treatments. They have also found some effect of temperature on endophyte infection.

How do climate and atmospheric changes soil carbon stabilization? 
- Researchers from Colorado State University (Richard Conant) collected soil samples during the harvest to assess how much carbon has been stabilized in different carbon fractions (using the $13 \mathrm{CO}_{2}$ tracer) and how that has been impacted by temperature.

\section{PUBLICATIONS (in 2008):}

In press:

Crutsinger GM, Reynolds WN, Classen AT, and Sanders NJ (2008) Disparate effects of plant genotypic diversity on foliage and litter arthropod communities. Oecologia 156:XX-XXX.

Knapp AK, Beier C, Briske DD, Classen AT, Lou Y, Reichstein M, Smith MD, Smith SD, Bell JE, Fay PA, Heisler JL, Leavitt SW, Sherry R, Smith B, and Weng E (2008) Consequences of more extreme precipitation regimes for terrestrial ecosystems. BioScience XX:XX-XXX.

Crutsinger GM, Sanders NJ, and Classen AT (in revision) Contrasting intra- and inter-specific effects on litter decomposition in an old-field ecosystem. Basic and Applied Ecology

In review:

Chen X, Post WM, Norby RJ, and Classen AT (in review) Modeling soil respiration and variation in source components using a multi-factor global climate change experiment. Climate Change

Antoninka A, Wolf JE, Bowker M, Classen AT, Johnson NC (in review) Linking above and belowground responses to global change at community and ecosystem scales. Global Change Biology

Engel EC, Weltzin JF, Norby RJ, Classen AT (in review) Responses of an old-field plant community to interacting factors of elevated $\left[\mathrm{CO}_{2}\right]$, warming, and soil moisture availability. Journal of Plant Ecology

Garten Jr. CT, Classen AT, Norby RJ (in review) Watering treatment surpasses elevated $\mathrm{CO}_{2}$ and temperature in importance as a determinant of soil $\mathrm{C}$ dynamics in a multi-factor climate change experiment. Plant and Soil

\section{Published abstracts (in 2008):}

Austin $\mathrm{EE}^{*}$, Castro HF, Classen AT, Nroby RJ, Schadt CW (2008- poster) Microbial community structure and climate change. Bulletin of the Ecological Society of America. Milwaukee, WI.

Campany C, Norby RJ, Classen AT (2008- talk) Influence of climate change factors on emergence, growth, and survivorship of woody seedling establishment in a constructed old-field community. Bulletin of the Ecological Society of America. Milwaukee, WI.

Cregger MA, Campany C, Classen AT (2008- poster) Effect of climate change on soil enzymatic activity in an old field community. Bulletin of the Ecological Society of America. Milwaukee, WI.

Gray S, Classen AT Kardol P, Yermakov Z, Miller RM (2008- talk) Water availability mediates the effects of temperature and $\mathrm{CO}_{2}$ concentration on soil microbial community composition. Bulletin of the Ecological Society of America. Milwaukee, WI.

Kardol P, Classen AT (2008- talk) Multifactor climate change: divergence in plant community composition drives changes in soil ecosystem functioning. Bulletin of the Ecological Society of America. Milwaukee, WI. 
Reynolds WN, Classen AT (2008- poster) Interactive effects of changes in atmospheric [ $\left.\mathrm{CO}_{2}\right]$, temperature and precipitation on microarthropod communities in an old field ecosystem. Bulletin of the Ecological Society of America. Milwaukee, WI.

Kardol P (2008 - invited talk) Soil nematode communities under climate change. 5th International Congress of Nematology, Brisbane, Australia.

Austin EE, Castro HF, Classen AT, Schadt CW (2008- poster) Citrate synthase: a functional genetic marker to study effects of climate drivers on soil microbial communities. American Society for Microbiology. Boston, MA.

Kardol P, Classen AT, Norby RJ (2008- invited talk) Multiple climatic changes and the structure and function of ecosystems: effects of atmospheric carbon dioxide, warming, and soil moisture on an old field ecosystem. Joint Meeting of the Society for Range Management and the American Forage and Grassland Council. Louisville, KY.

Garten JR. CT, Classen AT, Norby RJ (2007- poster) Changes in soil carbon and nitrogen in a multi-factor climate change experiment on constructed old fields. Bulletin of the American Geophysical Union. San Francisco, CA.

Norby RJ, Classen AT (2007- invited talk) Open-top chambers for investigating ecological responses to atmospheric and climatic change. ASA-CSA-SSSA Bulletin. New Orleans, LA. 